\section{Homotypic Cortex}

Maryellen Romero

Department of Psychiatry and Behavioral

Sciences, Tulane University School of Medicine,

New Orleans, LA, USA

\section{Synonyms}

Association cortex

\section{Definition}

Those areas of the neocortex in which the individual cellular layers are easily distinguishable (as opposed to idiotypic (primary) cortices in which layers 2 through 5 are more uniform). Homotypic cortex is generally further subdivided into unimodal and heteromodal association cortices, depending on whether it receives input from a single or multiple sensory modalities.

\section{Cross-References}

- Cerebral Cortex

- Heteromodal Cortex

- Idiotypic Cortex

- Unimodal Cortex

\section{References and Readings}

Mesulam, M. (2000). Behavioral neuroanatomy: Largescale networks, association cortex, frontal syndromes, the limbic system, and hemispheric specialization. In M. Mesulam (Ed.), Principles of behavioral and cognitive neurology (2nd ed., pp. 1-120). New York: Oxford University Press.

Stewart, O. (2000). Functional neuroscience. New York: Springer. 